\title{
Evaluation of Level of Heterogeneity of Socio-Economic Development of a Country
}

\author{
Valentinas Podvezko ${ }^{1}$ and Askoldas Podviezko ${ }^{2, *}$ \\ ${ }^{1}$ Vilnius Gediminas Technical University / Saulètekio al. 11, LT-10223 Vilnius, Lithuania \\ ${ }^{2}$ Vilnius Gediminas Technical University / Sauletekio al. 11, LT-10223 Vilnius, Lithuania \\ Mykolas Romeris University / Ateities g. 20, LT-08303 Vilnius, Lithuania
}

E-Mails: valentinas.podvezko@vgtu.lt; askoldas@gmail.com

* Author to whom correspondence should be addressed

Received: 12 September 2014 / Accepted: 27 October 2014 / Published: 1 November 2014

\begin{abstract}
Heterogeneity of levels of socio-economic development of countries or country's different regions is undesirable. For the sake of sustainable development of a country or group of countries it is important to elicit relative levels of development of country's regions or different countries, and to find the weakest indicators of their development. Socioeconomic development of a country or group of countries depends on a variety of factors. Statistics Department of Lithuania provides annual data describing the state of all 10 counties of Lithuania by 176 main criteria. The criteria describe economic development ( 80 criteria), social development (89 criteria), and finally, ecological state is described by 7 criteria. Prevailing in the literature comparative analysis by separately selected criteria, as important as GDP per capita, often does not provide an extensive picture of quality of life of country's citizens. A comprehensive approach is required for evaluating of level of development of countries or country's regions. A suitable tool, which promptly provides quantitative evaluation of level of development of country's regions, provides results in a clear comprehensible form, and comprises the whole variety of important multi-dimensional criteria is multiple criteria decision-making (MCDM) methods. Experienced experts evaluate weights of importance of criteria used in the research, keeping in mind the major aim of the evaluation. Weights and values of criteria are comprised into a single cumulative criterion of a MCDM method. Comparative analysis of evaluation over a lengthy period of time allows to analyse dynamics of development of the regions, and to elicit levels of
\end{abstract}


dependence of different criteria on the general level of development and welfare. MCDM methods allow revealing weaknesses of development of every region and provide a strong support for decision-makers and politicians for their effective actions intended for sustainable development of regions.

Keywords: sustainable development of regions, criteria, MCDM, comprehensive evaluation.

\section{Criteria of sustainable development of a country}

Heterogeneity of levels of socio-economic development of countries or country's different regions is undesirable. For the sake of sustainable development of a country or group of countries it is important to elicit relative levels of development of country's regions or different countries, and to find the weakest indicators of their development. Sustainable socio-economic development of a country or group of countries depends on a variety of factors. Statistics Department of Lithuania provides annual data describing the state of all 10 counties of Lithuania by 176 main criteria [1]. The criteria describe economic development ( 80 criteria), social development ( 89 criteria), and finally, ecological state is described by 7 criteria (Tables 1-3). The number of criteria is large, which inspires. Nevertheless, the set develops even further as every main criterion presented in the table consists of several sub-criteria, for which statistical data is also supplied. For example, the criterion "Water consumption by need", which is related to the ecological state, consists of 6 sub-criteria "Industrial", "Communal needs", "Energetic", Agricultural", "Fish breeding", "Other needs". And the criterion "Population by main source of livelihood" consists of 10 sub-criteria "Salary or wage", "Income from business", "Income from faming", "Income from property or investments", "Pension", "Benefit", "Grant", "State supported", "Supported by family and/or other persons", "Other source of livelihood".

Table 1. Economic criteria of sustainable development of a country.

1. Number of economic entities in operating.

2. Number of economic entities in operation by economic activity.

3. Number of economic entities in operation by personnel.

4. Total land used area.

5. Private land used for agricultural activity.

6. Crop area in all farms.

7. Crop area of grain in all farms.

8. Crop area of flax in all farms.

9. Crop area of sugar beet (for industry) in all farms.

10. Crop area of potatoes in all farms.

11. Crop area of vegetable grown in the open field
42. Volume of work carried out within the country by construction enterprises.

43. Dwelling completed.

44. Dwelling completed in one or two dwelling buildings.

45. New non-residential buildings completed.

46. Stock of dwellings.

47. Stock of dwellings by type of ownership.

48. Dwelling acquisition.

49. Restitution of ownership rights to residential houses.

50 Number of tenant families which have to be evicted from residential houses restituted to owners. 
in all farms.

12. Crop area of fodder roots including sugar beet for fodder in all farms.

13. Crop area of perennial grasses in all farms.

14. Grain harvest and yield in all farms.

15. Flax fibre harvest and yield in all farms.

16. Sugar beet (for industry) harvest and yield in all farms.

17. Potatoes harvest and yield in all farms.

18. Vegetable harvest and yield in all farms.

19. Number of cows in all farms.

20. Number of pigs in all farms.

21. Number of sheep and goats in all farms.

22. Number of horses in all farms.

23. Animals products recalculated in terms of milk.

24. Animals and poultry for slaughter in all farms.

25. Milk yield in all farms.

26. Productivity of animal and poultry in agricultural companies and enterprises.

27. Eggs production in all farms.

28. Wool sheared in all farms.

29. Grain crops, harvest and yield in farmers' and family farms.

30. Potatoes crops, harvest and yield in farmers' and family farms.

31. Number of livestock in farmers' and family farms.

32. Farm and land area.

33. Grouping of farms by area of agricultural land.

34. Grouping of farms by crop area.

35. Grouping of farms by number of cattle.

36. Grouping of farms by number of cows.

37. Grouping of farms by number of pigs.

38. Sales of industrial production.

39. Sales of industrial production, per capita.

40. Towns and districts municipalities as per cent in the national industry.

41. Production of main commodities.
51. Tenant families evicted from residential houses restituted to owners.

52. Number of persons (families) on the list for renting social housing.

53. Investment in tangible fixed assets.

54. Investment in tangible fixed assets per capita.

55. Foreign direct investment.

56. Foreign direct investment per capita.

57. Indicators of enterprises of retail trade including sale of motor vehicles.

58. Indicators of enterprises of sale, maintenance and repair of motor vehicles.

59. Indicators of enterprises of retail trade except sale of motor vehicles and motorcycles.

60. Indicators of restaurants, bars and other catering enterprises.

61 Service enterprises.

62 Income of service enterprises.

63. Export of goods produced in Lithuania.

64. Passengers carried by public buses.

65. Number of routes and trips by public buses.

66. Trolleybus communication.

67. Main residential telephone lines.

68. Number of individual passenger card per 1000 population.

69. Length of local roads.

70. Number of accommodation establishments.

71. Number of guests in accommodation establishments.

72. Overnights stays in accommodation establishments.

73. Number of hotels, rest and health establishments.

74. Number of guests in hotels, rest and health establishments.

75. Municipal budgets revenue and expenditure.

76. Tax revenue of Municipal budgets.

77. Municipal budgets expenditure by function of Government.

78. Gross domestic product (GDP).

79. Gross domestic product (GDP) per capita.

80. Structure of value added. 
Table 2. Social criteria of sustainable development of a country.

1. Total area, population and density.

2. Population by sex.

3. Annual average number of population.

4. Population by age group.

5. Fertility.

6. Mortality.

7. Mortality by cause deaths.

8. Infant mortality.

9. Natural increase/decrease.

10. Marriages.

11. Divorces.

12. Population migration.

13. Population by ethnicity.

14. Population by place of birth.

15. Population by other languages, which they know.

16. Population by religious confession.

17. Population by education.

18. Males and females by marital status.

19. Families by number of children.

20. Disabled children by sex.

21. Disabled persons by sex.

22. Population by main source of livelihood.

23. Buildings by period of construction.

24. Buildings by construction materials of the outer walls.

25. Population by conveniences in conventional dwellings.

26. Conventional dwellings by type of heating.

27. Average annual number of employed.

28. Employed population by economic activity and sex.

29. Employed by sex.

30. Unemployment by sex.

31. Labour force by sex.

32. Labour force activity rate by sex.

33. Employment rate by sex.

34. Unemployment rate by sex.

35. Unemployed registered with the Labour Exchange.

36. Unemployment rate.
44. Number of pre-school establishments.

45. Number of children by language of teaching in pre-school establishments.

46. Number of general schools.

47. Number of general daily schools.

48. Students studying foreign languages in general daily schools.

49. Teachers by education level in general daily schools.

50. Number of vocational schools.

51. Number of vocational colleges.

52. Number of colleges.

53. Number of universities.

54. Libraries.

55. Library worc indicators.

56. Cultural centres.

57. Cinema.

58. Museums.

59. Health care institutions.

60. Physicians.

61. Physicians by their practice.

62. Odontologists.

63. Nurses.

64. Number of pharmacists.

65. Number of hospital beds.

66. Morbidity by active tuberculosis.

67. Prevalence by active tuberculosis.

68. Morbidity by malignant neoplasms.

69. Prevalence by malignant neoplasms.

70. Number of visits to out-patient facilities.

71. Number of persons recognized as disabled for the first time, by group of disease.

72. Number of persons recognized as disabled for the first time, by disablement group.

73. Number of old-age pensioners paid by State Social Insurance.

74. Number of disability pensioners paid by State Social Insurance.

75. Total municipalities budgets expenditure on benefits for families bringing up children.

76. Recipients on municipalities budgets benefits 
37. Average number of employees converted into fulltime units by kind of economic activity.

38. Average monthly gross earnings by kind of economic activity.

39. Average monthly gross earnings in the whole economy by age of employee and length of service in the enterprise.

40. Average monthly gross earnings in the whole economy by major group of occupation and education.

41. Average retail prices for goods and services, December.

42. Changer in prices for consumer goods and services by group in bigger towns of the Republic. 43. Educational attainment of the population (ages 25-64). for families bringing up children.

77. Municipalities budgets expenditure on benefits for families bringing up children.

78. Municipal budgets expenditure on social benefits.

79. Registered criminal offences.

80. Registered crimes.

81. Registered murders and attempts.

82. Registered thefts.

83. Registered burglaries of dwellings.

84. Registered car thefts.

85. Registered robberies.

86. Cleared-up-crimes.

87. Juvenile delinquency.

88. Persons charged with crimes.

89. Juveniles charged with crimes.

Table 3. Ecological criteria of sustainable development of a country.

1. Water abstraction and consumption.

2. Water consumption by need.

3. Sewage discharge.

4. Air pollutant emissions from stationary sources.
5. Gaseous and liquid air pollutant emissions from stationary sources.

6. Average pollutant emissions from stationary sources $1 \mathrm{~km}^{2}$.

7. Emissions of SO2 and NOX from stationary pollutant sources.

Comparative analysis by each separate criterion, which is prevailing in the literature, even as important as GDP per capita often does not provide extensive picture of quality of life of country's citizens and the level of their satisfaction from the way they are able to fulfil their everyday needs. A comprehensive approach is required for evaluating level of development of countries or country $s$ regions, which would comprise social and economic state along with ecologic state in regions. A suitable tool, which promptly provides comprehensive quantitative evaluation of level of sustainable development of country's regions, provides results in a clear comprehensible form, and comprises the whole variety of important multi-dimensional criteria is multiple criteria decision-making (MCDM) methods [2].

Comparative analysis of results of MCDM evaluation obtained using values of criteria over a lengthy period of time allows to analyse dynamics of development of the regions. It is also possible to elicit levels of dependence of different criteria on the final result of evaluation. MCDM methods reveal weaknesses of development of every region and can provide a strong support for decision-makers and politicians for their effective actions required for sustainable development of regions.

There are many MCDM methods available, and neither single method has attained universal popularity. 


\section{The idea of the MCDM evaluation}

Some major steps of MCDM methods are similar throughout the methods. After the set of criteria for the evaluation is created experienced experts evaluate weights of importance of criteria used in the research keeping in mind the major aim of the evaluation. Then MCDM methods comprise weights and values of criteria into a single cumulative criterion of a MCDM method.

As a good example for illustration and description of the main idea of MCDM methods could serve the SAW (Simple Additive Weighting) method. Its cumulative criterion $S_{j}$, which represents the state of the $j$-th region is calculated by the formula (1) [3][4]:

$$
S_{j}=\sum_{i=1}^{m} \omega_{i} \tilde{r}_{i j},
$$

where $\omega_{i}$ is the weight of the $i$-th criterion, $\tilde{r}_{i j}$ - normalized (dimensionless) value of the $i$-th criterion of the $j$-th region.

Large number of main criteria and sub-criteria does not allow to directly use MCDM methods as experts can evaluate importance of no more than 10-12 criteria. Therefore, for evaluating the level of socio-economic development of regions of a country a hierarchy structure of criteria, characterizing situation in regions, must be created [3]. Criteria should be gathered into groups ("Environment and climate", "Population", "Employment and Unemployment", etc.), where the number of criteria becomes considerably smaller. Weights are estimated by experts for sub-criteria within each group, which is easier to accomplish now for the smaller number of sub-criteria. Consequently, weights for each main criterion (or category) are estimated. Beginning from lower levels of hierarchy and proceeding to higher levels economic, social [2][5][4][6] and ecologic [3] states of regions are evaluated separately. At the final stage comparative state of regions is evaluated.

\section{The new approach of creation the set of weights of a large number of criteria}

Widely used for quantitative evaluation statistical methods impose strict restrictions on data [7] [8]. Besides many well-known prominent features of MCDM methods [9] such methods do not impose any requirements on data. Multidimensional criteria are used for evaluation. It is therefore natural and even highly desirable to extend usage of the methods to the cases of a large number of criteria. The constraint of MCDM methods on the number of criteria is rather informal, but in reality experts are not able to evaluate relative importance of more than a dozen criteria. A way to overcome this obstacle a hierarchy of criteria where lower number of criteria are present at every its lowest level has to be built.

In our case the hierarchy may look as in Figure 1.

The proposed method of estimation of weights in the case of a large number of criteria is based on the idea that influence of each criterion on the above-level of hierarchy must be proportional both to the weight of the criteria within the category and to the weight of each entire category [mano in press]. It allows to estimate weights of criteria within each lowest-level category separately, and weights of each category of each higher level. As was mentioned, the hierarchy is built with intention to reduce both number of criteria within the lowest-level categories, and to reduce the number of categories in any higher-level category. Merging weights estimated for all categories of lower level with estimated category's weights obtained for criteria in higher category each lower-level category is effected by multiplying all weights as in formula (2). 
Figure 1. A hierarchy of criteria of sustainable development

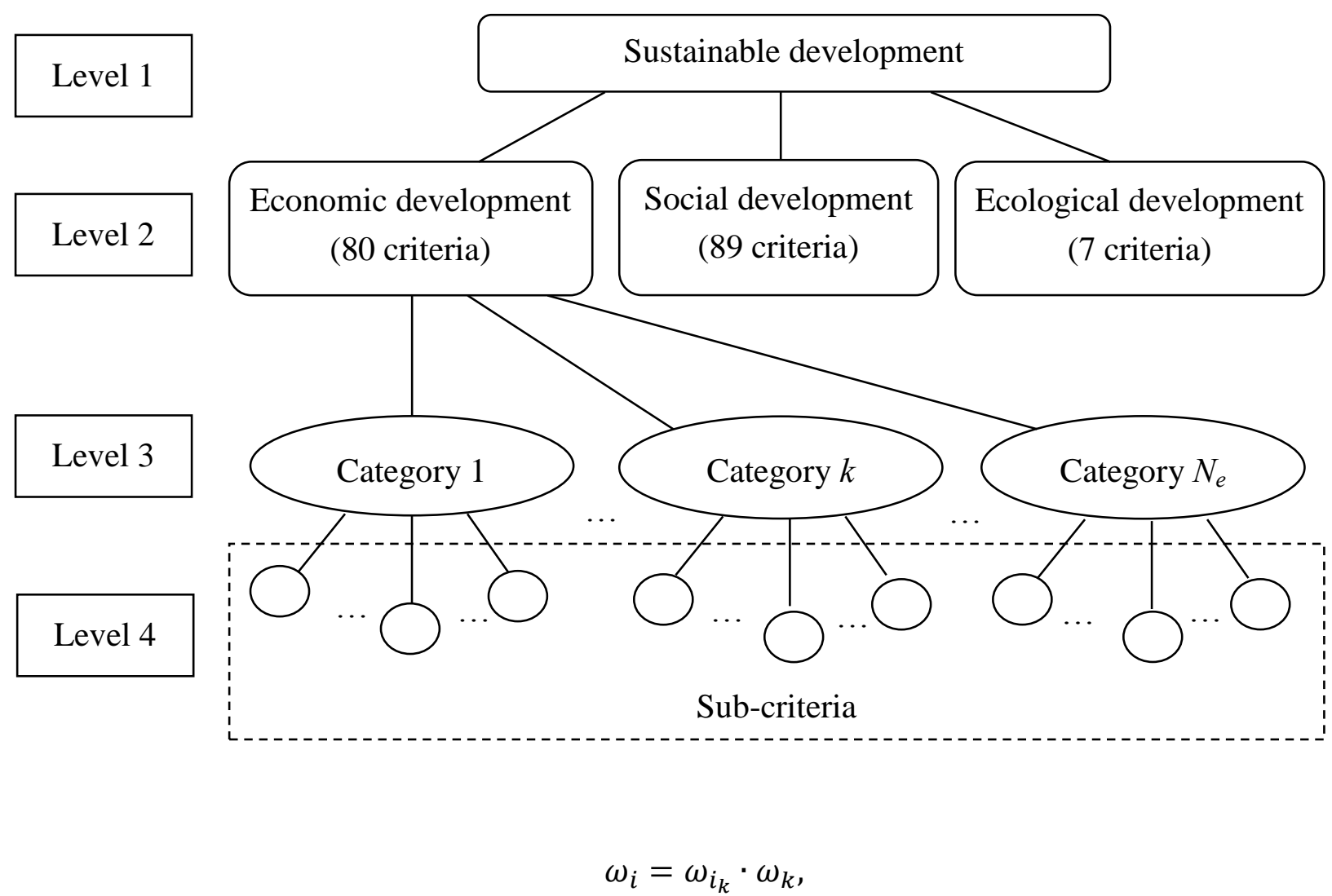

where $k$ is the index of categories, $i_{k}$ is the index of criteria within the category $k$. The sum of weights within categories equals to one, the sum of criteria $\omega_{i}$ also equals to one as well provided the weights were estimated correctly at each level of hierarchy, i.e. both sum of weights of allocated to all categories on each level equals to one, and sum of weights of criteria or sub-criteria within each category equals to one as well.

The proposed method is easy to use. The most difficult obstacle is to build a hierarchy, where number of both criteria in each category is sufficiently small, as well as the number of sub-categories within each category. The historically created hierarchies used in databases greatly reduce the required effort.

\section{Conclusions}

Widely used for quantitative evaluation statistical methods impose strict restrictions on data, which are not present in MCDM methodologies. It is therefore highly desirable to extend usage of the methods to the cases of a large number of criteria. Unfortunately, there is a constraint of MCDM methods on the number of criteria, which has to be limited to a rather small number, usually not larger than a dozen. A way to overcome this obstacle is creation of a hierarchy of criteria where lower number of criteria are present at every its lowest level.

The method of estimation of weights in the case of a large number of criteria was proposed. The method requires building a hierarchy of criteria, such as number of criteria within the lowest-level categories, and to reduce the number of categories in any higher-level category is reduced. 
The method is simple as it allows to estimate weights of criteria within each lowest-level category separately, and weights of each category of each higher level. In addition, it does not require complicated calculations.

Comparative analysis of results of MCDM evaluation obtained using values of criteria over a lengthy period of time allows to analyse dynamics of development of the regions. It is also possible to elicit levels of dependence of different criteria on the final result of evaluation. MCDM methods reveal weaknesses of development of every region and can provide a strong support for decision-makers and politicians for their effective actions required for sustainable development of regions.

Analysis of results allows to reveal economic, social and ecologic states of regions, their lagging in terms of identified criteria or categories and to provide a base for decision-making on finance allocation to the regions intended to smoothen inequality between regions.

\section{References and Notes}

1. Statistics Lithuania Counties of Lithuania; Lietuvos statistikos departamentas: Vilnius, Lithuania, 2011.

2. Brauers, W. K. M.; Ginevicius, R.; Podvezko, V. Regional development in Lithuania considering multiple objectives by the MOORA method. Technol. Econ. Dev. Econ. 2010, 16, 613-640.

3. Ginevicius, R.; Podvezko, V. Complex assessment of sustainable development of state regions with emphasis on ecological and dwelling conditions. Ecology 2007, 53, supplement, 41-48.

4. Ginevicius, R.; Podvezko, V. Housing in the context of economic and social development of Lithuanian regions. Int. J. Environ. Pollut. 2008, 35, 309.

5. Ginevicius, R.; Podvezko, V.; Mikelis, D. Quantitative evaluation of economic and social development of Lithuanian regions. Ekonomika 67-80.

6. Ginevicius, R.; Podvezko, V. Evaluating the changes in economic and social development of Lithuanian counties by multiple criteria methods. Technol. Econ. Dev. Econ. 2009, 15, 418-436.

7. Barniv, R.; McDonald, J. B. Review of Categorical Models for Classification Issues in Accounting and Finance. Rev. Quant. Finance Account. 1999, 13, 39-62.

8. Ravikumar, P.; Ravi, V. Bankruptcy prediction in banks and firms via statistical and intelligent techniques - A review. Eur. J. Oper. Res. 2007, 180, 1 - 28.

9. Zopounidis, C. Multicriteria decision aid in financial management. Eur. J. Oper. Res. 1999, 119, 404-415.

(C) 2014 by the authors; licensee MDPI, Basel, Switzerland. This article is an open access article distributed under the terms and conditions of the Creative Commons Attribution license. 